\title{
Eu não falo fluentemente nenhuma língua
}

\author{
Arnaldo Rosa Vianna Neto
}

Quem me escuta acha que minha língua é rude, que falo mal o francês. [...] Eu não falo, fluentemente, nenhuma língua. Eu compreendo mal o francês e mal o americano.*

Réjean Ducharme
" "Ceux qui m'écoutent trouvent que j'ai la langue rude, que je parle mal le français. [...] Je ne parle, couramment, aucune lan gue. Je comprends mal le français et mal l'américain" (Ducharme, Réjean. Le nez qui voque. Paris: Gallimard 1967:149).

O contexto dos anos 1960 se definiu política e culturalmente pelo redimensionamento das identidades nacionais. Visível em movimentos sociopolíticoculturais de contestação, a ruptura com os cânones hegemônicos ocidentais se marcou especialmente pelo episódio estudantil de maio de 1968 na França, as manifestações da contracultura em Woodstock nos Estados Unidos e a Revolução Tranqüila do Quebec ${ }^{1}$. Ao testemunhar divisões e contradições internas que identificam particularmente o ethos quebequense, a Revolução Tranqüila abalou instituições e expressou mudanças em estruturas éticas, culturais e ideológicas. No contexto em que ela se fez, a identificação etnocultural do cidadão quebequense como canadense-francês se destacou como uma das mais importantes questões do debate político no Quebec. $\mathrm{O}$ ato de reivindicação da cidadania quebequense tinha o estatuto de proposta ideológica e referendava a assunção de novas práticas de engendramento identitário, desenvolvidas principalmente ao longo do período em que se rompiam representações culturais neocolonialistas da ex-metrópole francesa, do Canadá anglófono e dos Estados Unidos, a nova metrópole pós-colonial. Na discussão, incluía-se também o Canadá, que, apesar da Independência, ainda não registrava, em suas formações discursivas, construções identitárias

${ }^{1}$ A Revolução Tranqüila se constituiu como o mito fundador de uma nova sociedade quebequense. Revolução institucional e cultural, mobilizou, na década de 1960, a sociedade civil no início de um processo de mutação identitária, transformação e legitimação do Estado quebequense. 
" (Ducharme, Réjean. Le nez qui voque. Paris: Gallimard, 1967).
" (cf. Hutcheon, Linda. Uma teoria da paródia. Lisboa: Edições 70, 1989)

" (cf. Santos, Eloína Prati dos. "A paródia pós-mo derna como ficção desco. Ionizante". Em: Peterson, Michel \& Neis, Ignacio Antonio (orgs.). As armas do texto: a literatura e a resistência da literatura. Porto Alegre: Sagra Lu. zzatto, 2000).

"(Moser, Walter. "La culture du recyclage". Em: Dionne, Claude : Mariniello, Silves tra \& Moser, Walter (dirs.). Recyclages. Économies de l'appropriation culturelle. Montréal: Les Éditions Balzac, 1996).

" (Canclini, Nestor. "Stra. tégies de recyclage". Em: Dionne, Claude : Mariniel Io, Silvestra \& Moser, Wal. ter (dirs.). Recyclages. Économies de l'appropriation culturelle. Ob. cit). nacionais capazes de fazer frente às políticas neocolonialistas desenvolvidas pelo vizinho estadunidense.

A crítica à cultura dominante e a leitura das formações discursivas culturais e sociais dos anos 1960 e 1970 no Quebec têm uma de suas expressões mais autênticas no escritor Réjean Ducharme. Definindo sua vontade política no sentido de uma ruptura com os modelos de organização política e cultural impostos pelos paradigmas neoliberais, Ducharme, em seus romances, critica e rejeita todas as formas de dominação, controle social, violência, alienação, escravidão e manipulação ideológica que subsistem na sociedade contemporânea ocidental como produto do capitalismo mercantilista global. Da obra de Ducharme, selecionou-se para análise neste artigo o romance Le nez qui voque*, por se tratar de uma narrativa que oferece ao pesquisador registro inestimável dos processos e mecanismos das construções identitárias canadenses e quebequenses. Nesse romance, elaborado durante as profundas rupturas com as formas estruturais de poder, Ducharme, ao articular identidade e extraterritorialidade na leitura da prática crescente de uma hibridização intercultural definida pelo nomadismo de imaginários diversos e complexos em trânsito em uma escrita também migrante, dá visibilidade a especificidades culturais do Quebec. A trama narrativa do romance se compõe de caricaturas de quem compactua de forma ativa, por convicção, ou passiva, por conivência ou covardia com ideologias submissas a sistemas responsáveis pela exclusão de alteridades ethoetnoculturais.

Apropriando-se, pelo exercício da paródia*, do memorial fragmentado que define o espaço nômade e o entrecruzamento de várias geografias memoriais, Ducharme constrói verdadeiros assemblages na mise-en-scène da problemática intercultural entre a hegemonia e a periferia, bem como reavalia os estatutos culturais na elaboração de uma territorialidade quebequense. Como sugestão de pesquisa do enigma textual anunciado no título de Le nez qui voque, e reiterado em outras linguagens artísticas praticadas por Ducharme, propõe-se neste artigo associar ao conceito de paródia como ficção descolonizante* o conceito de reciclagem cultural referenciado em Walter Moser* e em Nestor García Canclini*. Considera-se, em ambas as fontes, a recuperação dos danos da fragmentação cultural e a revitalização do modelo original como um produto híbrido, resultante de uma pluralidade de representações simultâneas que reivindicam o direito a um novo estatuto de verdade. 
Autor de inúmeros romances, peças de teatro, roteiros de filmes e composições musicais, Ducharme é também artista plástico, cujas montagens apresenta a mesma prática do assemblage $e^{2}$ que identifica seus romances. Suas peças, assinadas sob o pseudônimo de Roch Plante, são elaboradas com material sucateado e reciclado em composições complexas, e inscrevem no estatu to diferenciado do objeto artístico a ressignificação de conceitos e construções culturais esvaziados e imobilizados em paradigmas ideológicos hegemônicos. O bricoleur ${ }^{3}$ Roch Plante evoca, na metáfora inscrita no jogo do pseudônimo, a possibilidade de realizar a antiga problemática identitária quebequense, dividida entre os construtos culturais francófonos e anglófonos. A leitura de Roch como rocha, na língua inglesa, e Plante como planta, na língua francesa, pode sugerir combinações, como: rocha plantada em solo quebequense, no qual se identifica atualmente uma realidade plurietnocultural proliferando como "rizoma" na realização de uma hibridização até então inibida pela estrutura binária reprodutora do "pensamento de sistema" ou de "raiz única", que caracteriza os paradigmas hegemônicos ocidentais; semeador de pedras (recolhidas na errância do andarilho pelas fronteiras americanas na compulsividade da viagem como recurso para a sobrevivência cultural), que dissemina o ethos heterológico no solo quebequense.

Pode-se ler ainda, em uma intertextualidade semiótica, esse jogo de traduções que referenciam a pluralidade da identidade artística de Ducharme na figura cinematográfica do dompteur de vers" em Léolo* e dos protagonistas (mendigos, ratos de cidade) do filme Le joyeux calvaire ${ }^{*}$. O roteiro de Le joyeux calvaire reproduz o itinerário da errância de um mendigo pelas ruas de Montreal, realizando a temática da reinvenção do cotidiano que se lê na narrativa ducharmiana. Em Léolo, o romance L'Avalée des avalés* aparece como elemento
" (Glissant, Édouard. Intro. duction à une poétique du divers. Paris: Gallimard, 1996).

${ }^{2}$ Reunião e reciclagem de diferentes peças de sucata que resultam na montagem de um objeto artístico final com múltipla significação. Os inúmeros assemblages assinados por Ducharme se encontram no Musée du bas Saint-Laurent, no Quebec, ou no ateliê do artista.

${ }^{s}$ Denotativamente, pessoa que recompõe, repara, recupera; na metalinguagem artística, pessoa que se apropria de resíduos ou construtos culturais, conceitos, textos, composições, objetos artísticos preexistentes e subverte (criticamente) seu sentido, ao reciclar o material apropriado.

${ }^{4}$ Domador de versos; o que recicla, repara, recupera versos e sucata; bricoleur de versos e de sucata. A polissemia da palavra vers (poesia, versos, vermes, insetos) dá ao sintagma um sentido ambíguo explorado pelo autor no jogo da narrativa.

\footnotetext{
"(Lauzon, Jean-Claude. Léolo. Montréal, Québec. L'Office National du Film du Canada, 1992).

" (Arcand, Denis (dir.) \& Richard, Claire (scénario et dialogues). Le joyeux calvaire. Montréal, Québec. L'Office National du Film du Canada, 1997)

" (Ducharme, Réjean. L'Avalée des avalés. Paris: Gallimard, 1966).
} 
" (Plante, Roch. Skin. As. semblage sobre base de concreto, 1994). gerador da narrativa cinematográfica, ganhando representatividade de ícone narrativo quando o protagonista, o menino Léolo, exclui-se do núcleo familiar, canonicamente abjeto, para incluir-se no texto de Bérénice Einberg, protagonista do livro. Os dois personagens, aproximados pela lucidez de quem se reconhece na abjeção underground como sujeito de reconstrução de um ethos outsider, identificam-se e dialogam no espaço ambíguo de liberação e exclusão do discurso da infância. No filme, em cujo roteiro o diretor Jean-Claude Lauzon reduplica a reciclagem metafórica das narrativas de Ducharme, Léolo se aplica no exercício de uma escrita jamais concluída de versos que ele joga no lixo. Lauzon introduz na trama da narrativa cinematográfica a figura do dompteur de vers, que reproduz as práticas de Roch Plante em sua errância noturna pelas ruelas dos subúrbios de Montreal. O dompteur, dissimulado na figura de um catador de papéis, recolhe também os versos de Léolo, que, descobertos no anonimato do lixo, são submetidos à reciclagem do bricoleur, que os recompõe e re-identifica na narrativa afinal construída. Ao ficcionalizar a realidade cotidiana, Roch Plante atua ainda como bricoleur na reciclagem de material trash que perdeu sua funcionalidade junto à sociedade consumista submissa às ideologias do ter e à acumulação mercantilista. A prática de recolher, nas calçadas, sarjetas e latas de lixo, cacos, pedaços e restos de objetos danificados ou simplesmente rejeitados, como braços de bonecas, super-heróis de brinquedo e guimbas de cigarro, levou-o algumas vezes a ser identificado como mendigo. A ambivalência do sintagma dompteur de vers sugere a aproximação metafórica entre o personagem do filme de Lauzon e o artista plástico Roch Plante. Além da sucata, no saco do catador Roch Plante, encontram-se pedaços de papel de todo o tipo, como textos de revistas e jornais rasgados, bilhetes de teatro e cinema. Como o dompteur, ele os emenda e cola, realizando no bricolage de seus assemblages plásticos a prática narrativa do escritor Ducharme, outro duplo que ele vitaliza, negando-o.

Uma das práticas de Roch Plante é a de cobrir a base de concreto de alguns de seus assemblages, como Skin ${ }^{*}$, com jornais que veiculam comentários e artigos sobre sua obra, ressignificando a crítica em suas criações plásticas, ou usando da ironia no exercício paródico, ao lhe dar a função de embrulhar o lixo artístico. O reaproveitamento do trash recicla, assim, em suas composições o ethos desviante, movente e híbrido, tornando 
visíveis tais guetos culturais da cultura quebequense em uma construção dialógica polêmica com os referenciais europeus tradicionais e estadunidenses hegemônicos. Em Réjean Ducharme: une poétique du débris, Nardout-Lafarge referencia a legibilidade do processo de bricolagem cultural quebequense resultante da reciclagem identitária:

Talvez não seja irrelevante o fato de que nessa fragmentação, da qual permanecem apenas restos esparsos e esvaziados de sentido, os representantes da literatura e da cultura européias sejam radicalmente usurpados de seu texto, enquanto os enunciados quebequenses, truncados, cortados, continuem, apesar de tudo, legíveis.*

Em Le nez qui voque, a legibilidade dos enunciados quebequenses se encontra sob a forma de uma alegoria paródica da questão identitária do Quebec. Nesse sentido, pesquisaram-se na narrativa as representações do auto-engendramento da identidade quebequense, processo que inclui a territorialização no continente americano, ou seja, a ancoragem americana [arrimage américain] do quebequense e a inscrição de seu ethos no vocábulo “americano”. Nessa busca, identificou-se a recorrência de uma metafigura com estatuto de paradigma, que o sociólogo canadense Gérard Bouchard define e conceitua como representação do abastardamento [bâtardise] cultural nas Américas em "L’Amérique, terre d'utopie?":

[…] primeiro a recusa da mãe pátria nutriz, de suas tradições, normas e modelos, depois a instituição de novas referências resultantes de uma reapropriação simbólica do passado, do território, da língua, de si e do outro. [...] uma vontade de [...] escolherem suas raízes, seus ancestrais, repensarem suas origens, refazerem um passado, uma tradição, uma identidade. A aspiração a um auto-engendramento [...] proclamou-se alto e forte. Em muitos, esses ímpetos são traduzidos por uma apologia da insolência, da transgressão, da barbárie. Disso decorreu um importante trabalho de empréstimo, pirataria e bricolagem, resultando em uma cultura híbrida à qual o eclético agrada. Todos os traços que acabaram de ser evocados se apóiam em referências esparsas de numerosos intelectuais. Alguns autores, entretanto, associam-se mais estreitamente a isso, porque formularam quase integralmente em suas obras o paradigma do bastardo. Penso em três escritores (Jacques Brault, Réjean Ducharme, Jacques Ferron) e no filósofo Michel Morin.*
" (Nardouth-Lafarge, Éli. sabeth. Réjean Ducharme: une poétique du débris. Québec: Éditions Fides, 2001:103).

"(Bouchard, Gérard. "L'Amé rique, terre d'utopie?". Con ferência de abertura do Colloque interaméricain (Brésil-Canada) des scien ces de la communication. Salvador, setembro de 2002: 6-7). 
" "Hiérarchiser. Gide a écrit quelque part que c'est un mot horrible, affreux" (Du. charme, Réjean. Le nez qui voque. Ob. cit:25).
" "C'est une équivoque. C'est un nez qui voque. Mon nez voque. Je suis un nez qui voque" (:13).
Identificado assim o percurso do bastardo, sua figura ganha forma no jogo discursivo de Le nez qui voque, em que se criam tensões entre diferentes referências culturais sobre as quais tentam se legitimar determinados valores e códigos sociais. O rompimento com várias dessas referências determina a apropriação de outras na tentativa de construir no percurso do bastardo o auto-engendramento, a reafiliação como busca de autenticidade alimentada por referências locais ou continentais chamadas "americanas". Os mecanismos textuais de apropriação, transgressão e bricolagem que identificam o paradigma do bastardo são referenciais de leitura da cultura híbrida, eclética e complexa em Le nez qui voque. A escrita de Mille Milles, duplo narrativo de Ducharme, é o lugar de exercício de um dinamismo anárquico em que campos opostos, uma vez confrontados, reivindicam suas verdades construídas na resistência de um discurso ao outro, elaborando-se por meio do jogo da ambigüidade paródica. O anúncio do exercício discursivo é feito pelo narrador Mille Milles, que também é escritor: "Hierarquizar. Gide escreveu em algum lugar que esta palavra é horrível, medonha”* . Ao eleger a paródia e a reciclagem cultural como estratégias textuais para a prática da violação do modelo "imaculado”, Ducharme mascara com o estatuto do poético o referencial político de seu discurso. Apropriando-se das construções culturais estratificadas, o escritor transgride, ao longo do romance, seus interditos, recupera sua heterogeneidade enunciativa e as reescreve criticamente com os recursos lúdicos da ambigüidade e da ironia, privilegiados por ele na paródia textual. Escrevendo as representações nascidas da heterologia identitária cultural migrante, Ducharme se diverte nas viagens através de suas próprias narrativas com o logro que as representações verbais, distantes da paternidade castradora, podem produzir em um público leitor diferenciado. Desterritorializando a palavra, que mapeia outros territórios em busca da reciclagem de conceitos e da ressignificação de linguagens em trânsito nas complexas fronteiras heterológicas, recria o "Verbo" por intermédio da audição de outras vozes.

No romance, o trabalho de elaboração da língua(gem) ducharmiana se anuncia já no título, que nasce de um bricolage lingüístico composto da desmontagem e remontagem de fragmentos de um jogo de quebra-cabeças no qual se ressignificam palavras e sonoridades: "É um equívoco. É um nariz que voga. Meu nariz voga. Eu sou um nariz que voga"*, diz o protagonista 
de Le nez qui voque [O nariz que voga]. Ducharme manipula mecanismos polissêmicos, violentando ludicamente os códigos verbais em busca de uma interlocução com o próprio texto e fiel apenas à literariedade de seu assemblage textual. O escritor nega às palavras sua pretensão de codificar as relações sociais e reger a comunicação, optando pela multiplicidade polissêmica aberta ao jogo de produção de sentidos da linguagem literária. Mille Milles, o protagonista escritor da cidade narrativa de Ducharme, ao vaguear pelas bibliotecas, prefere a imagem gráfica das palavras a ouvi-las e, jogando com a produção dos sentidos que migram de uma palavra para outra, brinca com a forma das peças destacadas:

As palavras são igualmente belas, umas e outras. Um $u$ é mais bonito que um $i$, um $i$ menos bem torneado que um e? Uma palavra, para mim, é como uma flor: é composta de pétalas; é como uma árvore: é feita de galhos. Hierarquizar é uma montanha com doze flancos fantásticos e esses doze flancos são como os doze apóstolos. Os doze apóstolos se chamavam $H, I, E, R, A, R, Q, U, I, Z, A$ e $R$.

Les mots sont aussi beaux les uns que les autres. Un $u$ est-il plus joli qu'un $i$, un $i$ moins bien tourné qu'un $e$ ? Un mot, pour moi, c'est comme une fleur: c'est composé de pétales; c'est comme un arbre: c'est fait de branches. Hiérarchiser est une montagne à douze côtés fantastiques et ces douze côtés sont comme les douze apôtres. Les douze apôtres se nommaient $H, I, E, R, A, R, C, H, I, S, E$ et $R$.

"(: 25.6).

A ressignificação produzida nesse jogo de migrações aponta a constituição do non-sens ducharmiano, já anunciado no sintagma-chave, une équivoque (um equívoco), que produz o título do romance. À desmontagem inicial do sintagma, fragmentado em três unidades de sentido, nez, qui, voque, quando escandido em sílabas na construção do título, Ducharme, como bricoleur, sobrepõe inumeráveis combinações que desdobram a palavra équivoque em múltiplas possibilidades de leitura. Na composição do assemblage final, algumas das palavras que o bricoleur parece ter recolhido para o jogo de reciclagem são voque/ vogue (por aproximação homofônica), (ê)voque (por apócope do verbo évoquer), univoque e unéquivoque. Tomando-se vogue a partir da linearidade dos sentidos de vogar ou vagar/vaguear, no paradigma narrativo do romance, podem-se ler reproduções intertextuais que evocam (évoquer) a composição surrealista de um nariz "equívoco". Personificado e desmesurado, o "nariz" voga ou vagueia, dimensionando-se a carga denotativa dos 
"Elle m'a appris toutes sortes de jeux. - Jouons à compter. / - À compter quoi? / - N'importe quoi. Un bas. Deux bas. [... - C'est ça! J'ai un nez. J'ai deux nez. J'ai trois nez. J'a quatre nez. J'ai cinq nez. J'ai six nez. J'ai sept nez. J'ai huit nez. J'ai neuf nez. J'ai dîné" (: 333).

*uJ'aime la vérité età l'énoncer. Je n'aime pas l'ambiguitté. Êtes-vous à la recherche de la vérité?" (: 161)

" "Quelle sorte de littératu. re fais-je, Elphège? Est-ce de la littérature surréa. liste, surrectionnelle, ou surrénale? N'ajustez pas votre appareil. Cassez-lui la gueule. Laissez-le faire et allez-vous-en" (: 162)

" “Le beau n'est pas néces. sairement difficile à faire. Le beau n'est pas néces. saire. Le beau n'est pas. Le beau nez!" (: 9). vocábulos evocados com a acumulação conotativa dos sentidos a eles agregados.

A multiplicação de outras figuras associadas a esta é infinita e, como nas parlendas infantis, produz reiterações sucessivas de palavras que se ressignificam na produção de novos sintagmas, em uma reduplicação sem fim do jogo verbal e dos sentidos que migram de uma combinação a outra. Assim o é quando Mille Milles aprende o jogo verbal com sua amiga esquimó Ivugivic: "Ela me ensinou todo tipo de jogo. - Vamos brincar de contar. / - Contar o quê? / - Não importa o quê. Uma meia. Duas meias. [...] - É isso! Eu tenho um nariz. Eu tenho dois narizes. Eu tenho três narizes. Eu tenho quatro narizes. Eu tenho cinco narizes. Eu tenho seis narizes. Eu tenho sete narizes. Eu tenho oito narizes. Eu tenho nove narizes. Eu já jante»”*5.

Usando a auto-ironia, que também caracteriza seu exercício paródico, o escritor desconstrói a ambigüidade anunciada no título, quando afirma pela voz narrativa de Mille Milles seu amor à verdade: "Eu amo a verdade e gosto de dizer a verdade. Eu não gosto da ambigüidade. Você está em busca da verdade?”*, para voltar a afirmar, na parlenda interminável de seu texto, a opção pela insurreição surrealista inscrita na multiplicidade de sentidos da proposta estética contida no conceito: "Que espécie de literatura faço eu, Alfeu? É literatura surrealista, surrecional, ou supra-renal? Não sintonize seu rádio. Quebre esse rádio de uma vez. Deixe pra lá e vá embora"*6.

No bricolage resultante do jogo de desmontagem/remontagem do sintagma nez qui voque, Ducharme ressignifica ainda o conceito clássico do belo, ao usar a metáfora do nariz surrealista como ironia paródica e, reproduzindo a ambigüidade sugerida pelo sintagma-chave équivoque, evocar o equívoco conceitual que interroga as construções monolíticas do conceito: "O belo não é necessariamente difícil de produzir. O belo não é necessário. O belo não é. O belo nariz!"*. Mais uma vez, o escritor lança mão do recurso da parlenda e da apócope, exercitando o jogo contido no construto da língua(gem). Resta associar a esse

${ }^{5}$ Não é possível traduzir o jogo verbal homofônico entre nez e dîner. A tradução não representa o extrato fônico que resulta na rítmica interna do texto ducharmiano.

${ }^{6}$ A tradução de Elphège em Alfeu se faz apenas em uma tentativa de apreensão do jogo homofônico entre "fais-je" e "Elphège". Supõe-se, entretanto, que Elphège contenha múltiplos sentidos. Também a tradução da palavra surrectionnelle em "surrecional” foi feita em função do jogo homofônico e polissêmico, uma vez que não há correspondência em português. 
jogo a palavra-objeto unéquivoque, referenciada como uma das possibilidades do bricolage que anuncia com o título do romance o assemblage paródico do texto ducharmiano. A composição da forma unéquivoque, resultante da elisão do "e" do artigo indefinido no sintagma une équivoque, aparentemente vazia de significado, evoca a palavra univoque (un(équ)ivoque), produtora de ambigüidade em relação a équivoque, ressaltando-se, assim, a multiplicidade de sentidos do jogo do equívoco.

Em um caminho inverso, a desmontagem do bricolage do título (Le nez qui voque) levaria à remontagem do sintagma-chave une équivoque pela apócope do substantivo nez e a substituição do definido le pelo indefinido une, retomando-se o valor inicial de une équivoque. Qual seria, pois, a chave para a decifração do enigma contido no título? Ou, em outras palavras, qual o equívoco anunciado no título? A sedução do enigma condena o escritor Mille Milles (transeunte e navegador) a vagar no labirinto das ruelas da "cidade narrativa" de Ducharme, ou a vogar na eau courante da narrativa, recolhendo como bricoleur os cacos necessários à reciclagem textual. Cumprindo o estigma inscrito em seu nome (Mil Milhas), o personagem, duplo do autor, reproduz ao infinito o bricabraque narrativo como roteiro e fundamento de sua própria existência, que consiste em multiplicar irremediavelmente (e não em deslindar) o equívoco, a indecidibilidade do signo narrativo. Segundo Anne Élaine Cliche, analista da obra de Ducharme, o enigma gerador de seus romances seria o fantasma do logos autoritário e inequívoco do "Nome": "De onde vêm esses romances? Do horror do Nome, da negação que se expressa no texto sob as formas de um fantasma de destruição e aniquilamento"**

Em busca dessa identidade, o bastardo faz da língua(gem) um referencial novo, caracterizado pela hibridização da pluralidade de referenciais reciclados no processo de territorialização cultural canadense. Mille Milles, ao desconstruir relações entre enunciado e enunciação, traduz, na corrupção de cadeias de sons, outros registros do graphein, transgredindo a representação de significados preestabelecidos na sonoridade codificada dos significados. A narrativa de Le nez qui voque privilegia esse processo de desconstrução que se reitera em todos os seus romances. No sentido, pois, de fundador da paródia heterolingüística na narrativa de Ducharme, Mille Milles diz que o Canadá é "aca nada": "A palavra Canadá teria nascido dos espanhóis aca e nada que significam: nada aqui [...]. Pobre
" (Cliche, Anne Élaine. Le désir du roman (Hubert Aquin, Réjean Ducharme). Montréal: XYZ Éditeur, 1992: 81-2). 
" "Le mot Canada serait né des espagnols aca et nada qui signifient: rien ic [...]. Pauvre Mille Milles! Tout dépaysagé, tout dé sorientalisé, tout désillu. sionnismisé! Tout seul!" (Ducharme, Réjean. Le nez qui voque. Ob. cit.: 15).

" “Âpre Canada! Je ne parle, couramment, aucune lan gue. Je comprends mal le français et mal l'américain. Ceux qui m'écoutent trou vent que j'ai la langue rude, que je parle mal le français. Suis-je Français? Suis-je né à Paris? Je ne suis pas Fran çais. De plus, je ne veux pas être Français!" (:149).
Mil Milhas! Todo desorientado, todo desorientalizado, todo desiludido! Totalmente só!"*7.

A busca do significado etimológico de Canadá leva Ducharme a usar um de seus recursos narrativos produtores de paródias, o humor cáustico que desconstrói as formações estratificadas e indica pistas para a reciclagem identitária. Trata-se da necessidade latente de reinventar-se em um outro país, o da metaficção artística, e de reinventar o próprio país, pois, ao relacionar o significado de Canadá ao nada, o narrador rompe radicalmente com toda a representação conhecida do Canadá. Assim, quando Mille Milles diz que não é francês, não fala e não escreve o francês, e tampouco o inglês estadunidense, nega as duas maiores referências socioculturais e lingüísticas da história da construção do Canadá: "Áspero Canadá! Eu não falo, fluentemente, nenhuma língua. Eu compreendo mal o francês e mal o americano. Quem me escuta acha que minha língua é rude, que falo mal o francês. Eu sou Francês? Eu nasci em Paris? Eu não sou Francês. E mais, eu não quero ser Francês!”* Recusando a identidade monolítica e excludente, Ducharme propõe a construção de uma outra identidade nacional a partir da invenção de uma língua(gem) que aglutine repertórios etnoculturais diversos e desconstrua a estrutura binária maniqueísta.

Ducharme faz referência à antiga querela entre francófonos e anglófonos, ao expor a visão do país na concepção dos canadenses-franceses, para quem o Canadá pertence por direito aos primeiros dominadores, os franceses, que chegaram antes dos ingleses. Na verdade, esse binarismo é desigual, pois a concepção de Canadá-francófono foi elaborada pelos conquistadores ingleses. Não podendo excluir ${ }^{8}$ do Canadá a numerosa população da região que mais tarde se tornou o Estado [Province] do Quebec, os ingleses resolveram excluir culturalmente os primeiros conquistadores das novas terras, tidos como um

\footnotetext{
${ }^{7}$ Não é possível reproduzir em português o jogo verbal do texto. A palavra dépaysagé, que, por conter as palavras pays e paysage, quer dizer "sem paisagem/sem país”, ou seja, sem referência histórico-cultural, não tem correspondência em português. Assim também désillusionnismisé.

${ }^{8}$ Como se fez com os acadianos das províncias marítimas que, condenados à diáspora, migraram, em parte, para a Louisiana e o Quebec. A Acádia, primeira colônia francesa da América do Norte, foi cedida à Inglaterra pela França em 1713, em troca de algumas ilhas caribenhas. Seu povo, de origem francesa, expulso da Acádia pelos ingleses em 1755, no episódio conhecido como "a grande deportação", retornou parcialmente a ela a partir de 1763 , tornando-se conhecidos como "os retornados".
} 
apêndice inevitável, com a pecha de french, do canadensefrancês [french-canadian]. Os anglófonos deliberaram que os francófonos, se quisessem continuar a ser canadenses o fossem, mas assumissem o estigma cultural da marca preconceituosa imposta pelo rótulo french. Para os canadenses-anglófonos, o french representou não um acréscimo, mas uma "hifenização", confinando os canadenses-francófonos em um território cultural de exclusão. Isso contribuiu para o desenvolvimento de sua condição de bâtardise, uma vez que não se incluíam na carga semântica da palavra Canadá. Não podendo retomar para si o nome Canadá sem o estigma da pecha french e seu significado negativo imposto pelos anglófonos, os canadenses-franceses, inconformados com a exclusão, resolveram, a partir da Revolução Tranqüila, se auto-rebatizarem de quebequenses. $\mathrm{O}$ ato da autonomeação, como já se disse, faz parte da proposta ideológica e de suas práticas de auto-engendramento desenvolvidas principalmente ao longo desse período, quando romperam não só com as representações político-culturais da ex-metrópole francesa, mas também com as representações ligadas ao Canadá anglófono e as estadunidenses.

A quebra da quebehé(bé)tude*, ou seja, a letargia quebequense inscrita no lema "Eu me lembro" [Je me souviens] estaria na prática da coleta e da revitalização de materiais culturais trash, dispersos na excentricidade de linguagens, vozes, línguas e discursos sociais. O lema, afixado nas placas dos automóveis do Quebec, simboliza o compromisso com a manutenção da genealogia e do armorial de souche $e^{*}$, que imobiliza o quebequense francófono na glorificação de seu passado. Usando a ironia, Ducharme desconstrói, em Le nez qui voque, parte desse memorial que insiste em se perpetuar no imaginário quebequense. Essa ruptura aponta o processo de deserdamento [déshérence] europeu*, em que se concebe a metafigura do bastardo, característica da busca do auto-engendramento identitário no Quebec, como algo necessário ao quebequense para se livrar da herança que é uma das causas do mal-estar do herdeiro [malaise de l'héritier], a quebehé(bé)tude:

Quem quisesse se tornar canadense não conseguiria. Há quem tente muito se tornar canadense, os resistentes à americanização; eles fumam Gitanes, lêem L'Express, pilotam os Citroën,
Celui qui voudrait devenir Canadien ne pourrait pas le devenir. Il y en a qui essaient très fort de devenir Canadien, des durs à américaniser; ils fument des Gitanes, lisent L'Express, pilotent
Cafard; ennui; hébétude la hébétude du québécois (nostalgia; tédio; embo. tamento: a letargia do quebequense).

" Québécois de souche ou pure laine (quebequense de raiz ou de "lã pura").

"(Bouchard, Gérard. L'Amérique, terre d'utopie? Ob. cit : $6)$. 
vão aplaudir Luís Mariano, bebem o Château-Thierry, e empregam a palavra idiota. [...] Como odeio esses franceses frustrados, essas espécies de piromaníacos, que têm vergonha de ter nascido nestas margens, que prefeririam ter desembarcado nelas, que lamentam, sobretudo, não terem fracassado. [...] Eu não sou francês. E mais, eu não quero ser francês: é muito cansativo, é preciso ser muito inteligente, é preciso ser muito polido, é preciso ser bastante conhecedor de datas de vinhos, é preciso falar muito para nada, é preciso se considerar muito melhor que os outros. Eu jamais pus os pés na França; eu não sou francês. Douce ${ }^{9}$ França? Urgh! Acre Canadá! Eu não falo, fluentemente, nenhuma língua. [...] No final das contas, no início da colonização, francesa, questionou-se na França a troca do Canadá, no toma lá dá cá, por uma das Ilhas Virgens, uma das ilhas do mar das Antilhas. Isso não daria muito trabalho aos franceses para roubar o rei de França. No Canadá, fazia muito mais frio no inverno. Os franceses, colonizando nas Antilhas, não sentiam frio nos pés. Eles não queriam vir povoar o Canadá; fazia muito mais frio. A seda do gibão gelava. Agora des Citroën, vont applaudir Luis Mariano, boivent du ChâteauThierry, et emploient le mot con. [...] Que je hais ces Français manqués, ces espèces de pyromaniaques qui ont honte d'être nés sur ces rives, qui préféreraient y être débarqués, qui regrettent de ne pas avoir plutôt échoué. [...] Je ne suis pas Français. De plus, je ne veux pas être Français: c'est trop fatigant, il faut être trop intelligent, il faut être trop poli et trop connaisseur de dates de vins, il faut trop parler pour rien, il faut s'estimer trop meilleur que les autres. Je n'ai jamais mis les pieds en France; je ne suis pas Français. Doulce France? Pouah! Âpre Canada! Je ne parle, couramment, aucune langue. [...] Au début de la colonisation, française, il a été question en France que le Canada soit échangé, donnant donnant, contre l'une des îles Vierges, une des îles de la mer des Antilles en tout cas. Cela ne leur prenait pas beaucoup de place, pour voler le roi de France, aux Français. Il faisait beaucoup trop froid l'hiver. Aux Antilles, ils n'avaient pas froid aux pieds en colonisant, les Français. Ils ne voulaient pas venir peupler le Canada; il faisait beaucoup trop froid. Ils se gelaient la soie

${ }^{9}$ A tradução de doulce, que caracteriza a fonia do francês canadense com o enxerto do "l" no processo de oralização, corresponderia à fonia regionalizada no português "douce" (doce, suave), reproduzindo na escrita o enxerto da letra "u" resultante da oralização. Acrescenta-se assim ao significante, na escrita, a fonia do suplemento sociocultural-lingüístico diferenciado não inscrito na língua padrão. 
que o aquecimento central está instalado, eles se sentem menos constrangidos: eles vêm aqui nos colonizar, nos civilizar. du pourpoint. Maintenant que le chauffage central est installé, ils sont moins gênés: ils y viennent, nous coloniser, nous déniaiser. ${ }^{*}$
"(:149-50).

Apropriando-se do culto à pátria, à genealogia étnica e ao armorial de souche, Ducharme anuncia ironicamente sua proposta de desconstrução das formações sociopolíticoculturais que mobilizaram o imaginário canadense-francês: "Ó Canadá, minha pátria, meus avós, sua fronte, seus seios, seus florões gloriosos!"*. Ainda nesse sentido, ele critica o imobilismo das construções identitárias canadenses enraízadas nos cânones europeus e estadunidenses de onde se excluem as alteridades extraterritorializadas moventes: "Entre os Americanos, os que não cruzaram (a fronteira), porque já estavam do lado de cá, são os Canadenses, os vendidos, foi isso que os Americanos que atravessaram vieram comprar"*. Esse é o núcleo gerador de sua trama narrativa: o jogo entre as práticas migratórias, ou seja, o deslocamento entre fronteiras, a desconstrução e o remapeamento dos jogos de territorialização: “O Canadá é um vasto país vazio, uma terra sem casas e sem homens, menos no sul, menos ao longo da fronteira dos Estados-Desunidos, menos lá onde os Americanos transbordaram"*. A desconstrução de Estados-Unidos para Estados-Desunidos suplementa o material paródico da citação. Esse é um de seus exercícios de subversão da ordem: a prática de (re)territorializações cartográficas, políticas e culturais, que se dá a partir de uma redefinição de fronteiras redesenhadas pela forte dinâmica de mutações das construções sociopolíticoculturais produzidas pela homogeneização cultural-identitária ditada pela política hegemônica do Big Brother estadunidense. Com isso, pensa-se nas representações culturais migrantes e suas possibilidades de intervenção no jogo de poder nas Américas, em que a construção da americanidade se constitui também em uma estratégia de ação transnacional e de redefinição do aparato conceitual de fronteiras. Essa geometria cartográfica pode ser efetivada por jogos e combinações diversas, estratégias que permitam ao Quebec desenvolver mecanismos de reciclagem político-econômica e cultural além das fronteiras nacionais, possibilitando-lhe a inscrição de suas especificidades regionais em uma ecologia transnacional. Vale a pena lembrar que regiões e países ditos periféricos experimentam uma nova forma de colonialismo, um

" "Ô Canada, ma patrie, mes aïeux, ton front, tes seins, tes fleurons glo. rieux!" (: 148)

" "Ceux qui n'ont pas sauté (la frontière), qui étaient déjà de ce côté-ci, ce sont les Canadiens d'entre les Américains, ce sont les achetés, c'est cela que les Américains qui ont sauté sont venus acheter" (:148).

* "Le Canada est un vaste pays vide, une terre sans maisons et sans hommes, sauf au sud, sauf le long de la frontière des États. Désunis, sauf là où les Américains ont débordé" (:147). 
neocolonialismo aplicado pela globalização capitalista e predominantemente administrado pelos Estados Unidos. È assim que Ducharme exercita sua ironia no repúdio ao cafard, ao ennui, à letargia, mas também à exploração neocolonialista:

Dorme, Canadá, dorme; eu durmo com você. Fiquemos deitados, Canadá, até que um sol que valha a pena se levante. [...] Quem entre nós, meus irmãos, não é um apóstolo de Popeye, de Woody o Pica-pau, de Papai tem razão, da Dodge, da Plymouth, da Chrysler, dos carburadores entupidos, do chá-chá-chá, da Coca-Cola, do Seven-Up, de Jerry Lewis e de Tcharles ${ }^{10}$ Boyer? Quem, aqui, tem a coragem de ir quebrar a cara dos cantores pagos pelos vendedores de Pepsi, cantores que cantam nem mais nem menos que somos a geração Pepsi? Àqueles que não estão a par disso, que não captam os postos da rádio canadense, informo que a Pepsi é um líquido dos Estados-Desunidos, uma espécie de Coca-Cola.
Dors, Canada, dors; je dors avec toi. Restons couchés, Canada, jusqu' à ce qu'un soleil qui en vaille la peine se lève. $[\ldots]$ Qui d'entre nous, mes frères, n'est pas un apôtre de Popeye, de Woody the Woodpecker, de Papa a raison, de la Dodge, de la Plymouth, de la Chrysler, des carburateurs enrhumés, du cha-cha-cha, du Coca-Cola, du Seven-up, de Jerry Lewis et de Tcharles Boyer? Qui, ici, a le courage d'aller casser la gueule aux chanteurs payés par les vendeurs de Pepsi, chanteurs qui chantent ni plus ni moins que nous sommes de la génération Pepsi? Pour ceux qui ne seraient pas au courant, qui ne captent pas les postes de radio canadienne, je précise que le Pepsi est un liquide des États-Désunis, une sorte de Coca-Cola.*

A assimilação por grande parte da população canadense do ethos sociocultural e dos paradigmas políticos e econômicos estadunidenses é ironicamente criticada e caricaturada no texto ducharmiano, quando, além de reivindicar um Canadá para os canadenses, nega a seus habitantes a identidade canadense: "Eles dizem que há vinte milhões de canadenses. Para onde foram?”* . Como se sabe, mesmo após a constituição do Canadá em país e até a Revolução Tranqüila, sua população, oo menos no Quebec, dividiu-se entre as referências culturais identitárias francesa e inglesa. O referencial das ex-metrópoles foi, de todo modo, substituído por outros referenciais neoco-

${ }^{10}$ A manutenção da letra “T” de Tcharles, na tradução, deve-se à reprodução de processo semelhante em português na oralização da língua escrita. 
lonialistas impostos pelo vizinho estadunidense: "Quem, no Canadá, não é da raça dos cachorros-quentes, dos hamburgers, do churrasco, dos chips, das torradas, dos edifícios, dos stops, do Reader's Digest, de Life, da Metro Goldwin-Mayer, do rock'n'roll e do bouillie-bouillie?”* . Nos outros estados canadenses, salvo algumas exceções de coletividades francófonas, cujo contingente demográfico não é tão expressivo quanto o do Quebec, os cidadãos de maioria anglófona também sofriam, como ensina o texto de Ducharme, problemática semelhante com relação à não “ancoragem” de seus ethoï dependentes das influências estadunidense e inglesa, o que permitiria dizer, em resumo, que o Canadá não conhece o próprio Canadá: “O Canadá é. O Canadá é ou não é? [...]. No Canadá, agora, não há mais ninguém, senão o embaixador do planeta Marte, que não seja americano"*.

A construção de uma identidade nacional compósita, entretanto, parece distante, apesar dos ardis políticos multiculturalistas em estimular a inclusão desses registros (referenciados por Ducharme em Le nez qui voque) no sistema cultural identitário vigente, com o objetivo de desviar a atenção da problemática identitária cultural entre francófonos e anglófonos. Argumenta-se que os quebequenses estariam se beneficiando do binarismo maniqueísta para ganhar espaço político junto ao Governo Federal canadense e buscar a inclusão das representações culturais francófonas junto às instituições federais. Essa constatação originou um investimento político por parte de Ottawa nas políticas multiculturalistas que dispersariam a articulação crescente do segmento quebequense em luta por uma maior representatividade sociopolíticocultural no contexto canadense e/ou pela emancipação do Quebec. Em suma, é importante lembrar que foi graças às políticas multiculturalistas que o governo canadense evitou, quando do referendum de 1995, a emancipação política do Quebec, uma vez que as populações imigrantes, concentradas sobretudo em Montreal e estimuladas por essas políticas, votaram contra a independência da Province, constituindo-se como o "fiel da balança".

Apesar do discurso fortemente político de Le nez qui voque, Ducharme, fiel à sua poética, alerta o leitor para um possível equívoco na leitura de sua narrativa: "Não se deve me levar a sério. Eu não faço nada senão repetir o que ouvi dizer. Não acredito em uma só palavra do que digo. Eu não creio em nada. Isso já é demais. [...] Para resumir: pouco me importa"*.
" "Qui, au Canada, n'est pas de la race des hot-dogs, des hamburgers, du bar-b-q des chips, des toasts, des buildings, des stops, du Reader's Digest, de Life, de la Metro Goldwyn-Mayer, du rock'n'roll et du bouillie. bouillie?" (: 148).

" (cf. Létourneau, Jocelyn. Passer à l'avenir. Histoire, mémoire, identité dans le Québec d'aujourd'hui. Montréal: Boréal, 2000).

" "Le Canada est. Le Canada est-il ou n'est-il pas? [...]. Au Canada, maintenant, il n'y a plus que l'ambassadeur de la planète Mars qui ne soit américain" (Ducharme, Réjean. Le nez qui voque. Ob. cit: 148).

" "Il ne faut pas me prendre au sérieux. Je ne fais que répéter ce que j'ai entendu dire. Je ne crois pas un seul mot de ce que je dis. Je ne crois en rien. En voilà trop. [...] Pour résumer: je m'en fiche" (:152) 


\section{Arnaldo Rosa Vianna Neto}

Doutor em Literatura Comparada e Mestre em Literaturas Francófonas pela Universidade Federal Fluminense. Atualmente, faz pesquisa de Pós-Doutorado na UFRJ. É professor de francês na Universidade Estácio de Sá (UNESA/RJ) e professor substituto de Língua e Literatura Francesas na UFRJ.

Palavras-chave

alteridade

bastardo

identidade paródia reciclagem

Key words

alterity

bastard

identity

parody

recycling

Mots-clé

altérité

bâtard

identité

parodie

recyclage

\section{Resumo}

No contexto dos anos 1960, marcado por contestações culturais e rupturas ideológicas com paradigmas hegemônicos ocidentais, a Revolução Tranqüila do Quebec produziu profundas mudanças culturais, expressando contradições internas do ethos quebequense. Nesse quadro, a obra do escritor Réjean Ducharme é considerada a expressão do romance americano no Quebec. No jogo discursivo do romance Le nez qui voque, publicado em 1967, engendra-se a representação do abastardamento cultural nas Américas sob a forma de uma alegoria paródica da questão identitária do Quebec. Elaborado durante as profundas rupturas com as formas estruturais de poder, o romance articula identidade e extraterritorialidade na leitura da prática crescente de uma hibridização intercultural definida pelo nomadismo de imaginários diversos e complexos em trânsito em uma escrita também migrante. $\mathrm{O}$ processo inclui a territorialização do quebequense no continente americano, ou seja, a representação do referencial cultural identitário americano do quebequense e a inscrição de seu ethos no vocábulo americano.

\section{Abstract}

In the 1960', a context characterized by cultural movements and ideological ruptures with hegemonic western paradigms, Quebec's Quiet Revolution produced deep cultural changes, expressing inner contradictions of the Quebecer ethos. In this panorama, Réjean Ducharme's work is considered the expression of Quebec's American novel. In Le nez qui voque's discursive play, a novel published in 1967, one engenders the representation of the cultural degeneration of Americas under a parodic allegory of Quebec's identitary question. Developed in the deep

\section{Résumé}

Dans le contexte des années 1960, signalé par des contestations culturelles et des ruptures idéologiques avec des paradigmes hégémoniques occidentaux, la Révolution Tranquille au Québec a produit de profonds changements culturels, exprimant ainsi des contradictions internes de l'ethos québécois. Dans ce cadre, l'oeuvre de l'écrivain Réjean Ducharme est considérée comme l'expression du roman américain au Québec. Dans le jeu discursif de Le nez qui voque, roman publié en 1967, la représentation de la bâtardise cuturelle aux Amériques est engendrée 
ruptures with the structural forms of power, the novel articulates identity and extraterritorialization in the reading of the growing praxis of a cultural hybridization defined by the nomadism of diverse and complex imaginary in transition in a migrant writing. The process includes the Quebecer's territorialization in the American continent, that is, the representation of the Quebecer's American identitary cultural reference and the inscription of his ethos in the Americain word. par une sorte d'alégorie parodique de la question identitaire au Québec. Élaboré pendant les profondes ruptures avec les structures du pouvoir, le roman articule identité et extraterritorialité dans la lecture de la pratique croissante d'une hybridation interculturelle définie par le nomadisme d'imaginaires divers et complexes en circulation dans une écriture aussi migrante. Le processus inclut la territorialisation du québécois dans le continent américain, c'est-à-dire, la représentation du référentiel culturel identitaire américain du québécois et l'inscription de son ethos dans le vocable américain.
Recebido em 19/04/2006

Aprovado em 09/06/2006 